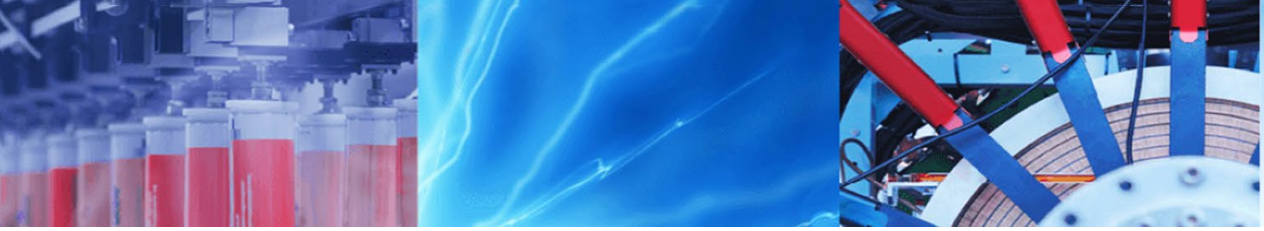

Research Article

\title{
Analysis of the implementation of microgrid: case study of wide-area Bjelimići
}

\author{
Lejla Terzićc ${ }^{1}$ • Aiša Ramović ${ }^{1} \cdot$ Ajla Merzić $^{2} \cdot$ Adnan Bosović $^{2} \cdot$ Mustafa Musić $^{2}$
}

(c) Springer Nature Switzerland AG 2018

\begin{abstract}
Microgrids are increasingly put forward as key concepts of future energy supply, complementing as well as transforming the conventional, centralized energy system. Here, the aim was to construct microgrid composed of wind and solar power plants, diesel generator and battery storage which will be independent of a large, centralized electricity grid and incorporate more than one type of power source so to supply Bjelimići area. This area is taken as a case study since it has large potential considering the renewable energy sources and because this feeder is quite long which makes energy losses considerably higher. All material which were used in this project consist of real network parameters which are provided by Public Electric Utility Elektroprivreda of Bosnia and Herzegovina. For completing the project, DIgSILENT PowerFactory software (base package and Quasi-Dynamic Simulation Toolbox), HOMER (Hybrid Optimization Model for Multiple Energy Resources) software and Microsoft Excel were used. System has been modeled using minimum total cost of investment as a goal for optimization function and to cover the maximum power load with battery storage and diesel generators. Therefore, appropriate installed power of wind, solar and diesel power plants in combination with battery storage, based on real energy resource data and real load profiles of existing customers, has been chosen. In the end, using obtained data from HOMER for model in DIgSILENT PowerFactory, power flow, voltage profiles, line and transformer loading, and total grid losses were analyzed. It has been concluded that microgrids should be considered as excellent solution for such and similar areas, especially when considering the construction or significant upgrading of networks. Also, results from DIgSILENT PowerFactory have proved that system can operate with modeled microgrid. In addition, it is shown that better conditions of the network are present when operated in the island mode.
\end{abstract}

Keywords Microgrid $\cdot$ Hybrid power systems $\cdot$ HOMER $\cdot$ DlgSILENT PowerFactory

\section{Introduction}

One way to increase reliability and quality of electrical power supply in advanced power generation networks is the integration of distributed production, energy storage and energy management on level of microgrids and distribution networks. Benefits of distributed production are reduction in transmission and distribution losses, improved utilization of energy sources, shorter construction time and possibility of production at all voltage levels.
Hybrid power systems (HPS) are designed for the generation and use of electrical power. They are independent of a large, centralized electricity grid and incorporate more than one type of power source. They may range in size from relatively large island grids of many megawatts to individual household power supplies on the order of one kilowatt. In general, a hybrid system might contain AC diesel generators, DC diesel generators, an AC distribution system, a DC distribution system, loads, renewable power sources (wind turbines, photovoltaic power sources, small

$\triangle$ Lejla Terzić, lejla.terzic@stu.ibu.edu.ba| ${ }^{1}$ Department of Electrical and Electronics Engineering, Faculty of Engineering and Natural Sciences, International Burch University, Sarajevo, Bosnia and Herzegovina. ${ }^{2}$ Department of Strategic Development, Public Electric Utility Elektroprivreda of Bosnia and Herzegovina, Sarajevo, Bosnia and Herzegovina. 
hydro power plant), energy storage, power converters, rotary converters, coupled diesel systems, dump loads, load management options or a supervisory control system [1].

Analysis in [2] focuses on the comparative analysis between HPSs on a microgrid and the supply option over the transmission and distribution network. Autonomous HPSs are conceptualized by taking into account storage in the electric vehicles of guests and employees within the treated example of the winter tourist center. In this way, a possible future concept for a sustainable power supply is proposed, focusing on locally available RES utilization and capacity optimization, in accordance with real indicators at the site.

Hassan et al. [3] mention the need for hybrid power systems and its advantages. The HOMER software is used to study and design the proposed hybrid energy system model. Based on simulation results, it has been found that renewable energy sources perhaps replace the conventional energy sources and would be a feasible solution for the generation of electric power at remote locations with a reasonable investment [3]. Despite the comparatively high cost of electricity from distributed generation units, microgrids can be a valuable investment opportunity. This is especially true in cases where a high value is placed on improving or maintaining reliability or power quality (such as in military installations or rural networks), where customers want to improve their environmental impact, or in systems in which imminent investments are needed to ensure or improve local reliability or power quality [4]. Also, in [5], based on proposed framework of microgrids and control strategy, the models of distributed generations were built in DIgSILENT PowerFactory. Different cases were analyzed, and the simulation results show that the framework conforms power grid feature and the control strategy can ensure safety and reliable operation under different situation.

The term microgrid refers to the power system with distributed energy sources and should not be rated by the size of the network, but by its function. The existing power system has to deal with the development of technology and society, as well as economic problems. The system, issues and protection in the power system is a demanding challenge for power engineers, and the need for a secure power system is paramount. The quality of electricity must be of adequate characteristics, and the energy should be constantly available, the electricity supply costs must be optimal, and energy efficiency should be present in all aspects of energy consumption. These challenges play a major role in the development of a microgrids, an energy network that should cover the disadvantages of today's known systems to improve the production and use of electricity. The microgrid can work in an island mode that is very useful when it comes to any failure, as well as in bringing electricity to remote areas, but the problem of this mode of operation is the control of frequency, voltage, reactive and active power [6]. Likewise, the microgrid can work parallel with the existing network where the system operator is supervising it as a manageable entity. The microgrid supports a flexible and efficient electrical network, enabling the integration of renewable energy sources. In addition, using local power sources that reduce the load on the existing network reduces losses in transmission and distribution and thus increases the efficiency of the electricity delivery system [7].

The distribution system energy system needs to evolve to facilitate such access to distributed generation based on renewable energy sources and to establish a communication system that will enable interaction with end users to gain data on the amount of energy required. The presence of distributed sources slowly transforms the distribution network from the passive network into active, resulting in some branches of the network changing the direction of power flows [8]. The active network requires new equipment and services, voltage control, system protection and calculation of power flows, which makes it harder for the job of the system dispatcher. But the main function of such a network is, of course, to equalize production and consumption of electricity in real time.

Microgrid organization is based on control properties over a grid containing microturbines, fuel cells and photovoltaic power plants together with energy storage systems and fuel cells. This system enables continuous supply in case of failure, disaster or any other disruption that can interrupt power supply [9]. The key potential of microgrids lies in the ability of end users to use, on a local level, the proper use of any unused heat that is product of electricity generation, especially households in colder countries. From the standpoint of usability, application of microgrid can reduce the need for distribution and transmission units. For example, distributed production near the load can have very beneficial effects on the system in reducing power flows in the transmission and distribution network, which leads to loss reduction. Microgrid, in situations of large loads, can be support to network. All the microgrid characteristics mentioned are sufficient evidence that it is necessary to develop a new concept of the power system in a rapidly evolving world and for which such a change is needed [9].

Microgrids can operate in two modes, grid-connected and Island mode. In [10], there has been a keen interest on distributed generation (DG) due to their restricted goals of meeting local loads and improving reliability of the overall system. Microgrids (MGs) are connected to the main grid through a point of common coupling which separates the former from the latter. At the time of an intentional 
islanding or fault at the grid level, a microgrid is able to disconnect itself from the rest of the grid and operate by itself. A microgrid may contain both directly connected and inverter interfaced sources with different control configurations. When disconnected or islanded from the main grid, there are various approaches to share the load, one of them being master-slave control where a storage device may become the reference DG to set the nominal voltage and frequency [10].

The research study is fueled by the following objectives: Since Bjelimići area is somehow critical based on the fact that feeder is very long which causes big power losses, it is important to analyze and choose appropriate solutions for this case. First is to choose the appropriate installed power of wind, solar and diesel power plants in combination with battery storage, based on real energy resource data and real load profiles of existing customers. Aim is to achieve minimum total cost of investment for HPS as a goal for optimization function and to cover the maximum load with battery storage and diesel generators. This is obtained in HOMER software, and then, entering obtained results in the real network model in DIgSILENT PowerFactory, in a way to investigate possibility of network operation. Now, when positive results are obtained, further operations and improvements on this microgrid can be performed. These should be including two modes of operation, grid-connected mode and Island mode. Due to the criticality of this area, there would be big investments, but in very end the investment should be returned.

\section{Materials and methods}

Bjelimići is community of villages located in the southeastern part of the municipality of Konjic. Konjic is located in northern Herzegovina and is mountainous, heavily wooded area. Bjelimići is wide, hilly area between the mountains Visočica, Treskavica and Crvnja, and is $1000 \mathrm{~m}$ above sea level. It has great potential for installing renewable energy resources on this area.

Figure 1 shows the georeferenced scheme of the medium voltage distribution network in analyzed area Bjelimići.

Besides complete topology and georeferenced scheme, the materials used in this paper consist of real network parameters of components (transformers, lines, loads) in the feeder $10 \mathrm{kV}$ Lađanica, then load profiles of loads (mostly village houses) on TS 10(20)/0.4 kV Odžaci and TS 10(20)/0.4 kV Luka, in 15-min intervals for 1 year (2016) and wind potential and solar insolation measurement data from wind atlas and PVGIS.

According to load profile of this area, data for PV, wind and diesel generator will be taken from PVGIS, wind atlas

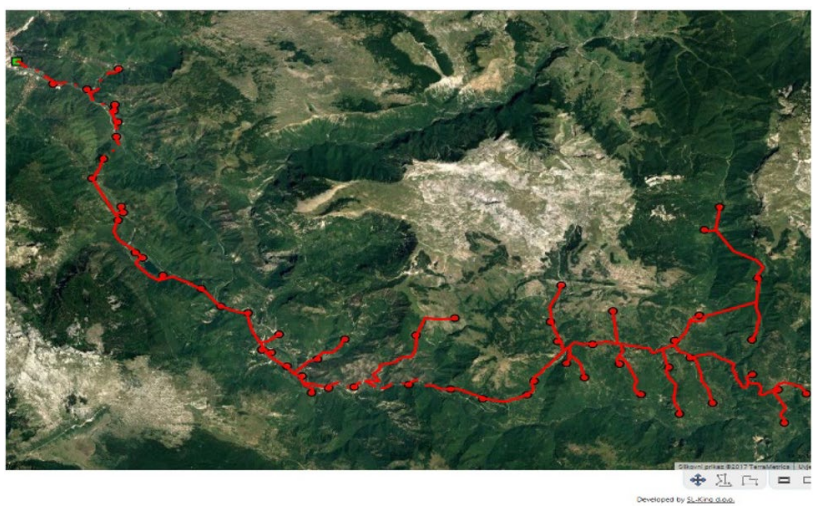

Fig. 1 Georeferenced scheme of the area Bjelimići

Table 1 System architecture in HOMER

\begin{tabular}{llll}
\hline PV & ABB Trio-50.0 with generic PV & 50 & kW \\
Wind turbine & Northern power NPS100C-21 & 100 & kW \\
Generator & $\begin{array}{l}\text { Generic 100 kW fixed capacity } \\
\text { Genset }\end{array}$ & 100 & kW \\
Storage & Tesla 50 kW Powerpack 2 & 210 & kWh \\
Converter & System converter & 0.990 & $\mathrm{~kW}$ \\
Dispatch strategy & HOMER load following & & \\
\hline
\end{tabular}

and HOMER generators catalogue, respectively. After entering this into HOMER software, appropriate HPS configuration will be established, based on least-cost investment optimization.

The load following strategy is a dispatch strategy whereby whenever a generator operates, it produces only enough power to meet the primary load. Lower-priority objectives such as charging the storage bank or serving the deferrable load are left to the renewable power sources. The generator can still ramp up and sell power to the grid if it is economically advantageous [11] (Table 1).

The real network will be modeled in DIgSILENT PowerFactory software, but due to the limited number of buses that are allowed with used software license, the certain parts of network would be implemented as equivalent loads. For modeling microgrid in this software, data obtained from HOMER will be used. Two modes of operation will be analyzed, grid-connected and island mode. For both cases, two scenarios will be obtained, winter and summer scenarios. After this, power flow, voltage profiles, line and transformer loading, and total grid losses will be compared and analyzed.

\section{Results and discussion}

Results section will be divided into two subsections, one for results from HOMER and another for results from DlgSILENT PowerFactory (Table 2). 


\subsection{HOMER}

In this section, the analysis results will be presented and shortly discussed. The goal was to design hybrid power system which will meet the needs of consumers and get minimal total cost of investment which will be presented through table results and charts. In Table 3 and Fig. 2, net present costs of all elements used in designing hybrid power system and cost summary are shown, respectively. The prices in Table 3 are obtained as a result from HOMER software, and it is important to mention that they depend on the region and are subject to change.

The HPS presented in this paper produces $498,173 \mathrm{kWh}$ per year with total NPC of $937,670 \mathrm{KM}$ for project lifetime of 25 years, while consumed energy for 25 years equals to $3,430.825 \mathrm{MWh}$. If this consumed energy is delivered to consumers via power grid network, it will cost $461,789.045 \mathrm{KM}$ (cost for single-tariff meters of $13.46 \mathrm{pf} / \mathrm{kWh}$ ), which is lower than total investment cost for proposed HPS. Even the total NPC cost of the HPS is lower than costs of electricity bought from centralized production units. However, electricity from a centralized system requires high costs of MV network construction as well as losses in the MV network; $1 \mathrm{~km}$ of main MV overhead line with uninsulated conductors costs approx. $65,000 \mathrm{KM}$, and there are tens of kilometers of highway line. Besides, this implementation will lead to $\mathrm{CO}_{2}$ emissions reduction and many other social and consumers' satisfactions. In any case, when considering the construction or significant upgrading of networks for such and similar areas, microgrids should be considered as excellent solution.

Table 2 Production summary

\begin{tabular}{lc}
\hline Component & Production $(\mathrm{kWh} / \mathrm{y})$ \\
\hline ABB Trio-50.0 with generic PV & 94,308 \\
Generic 100 kW fixed capacity Genset & 84,218 \\
Northern power NPS100C-21 & 319,647 \\
Total & 498,173 \\
\hline
\end{tabular}

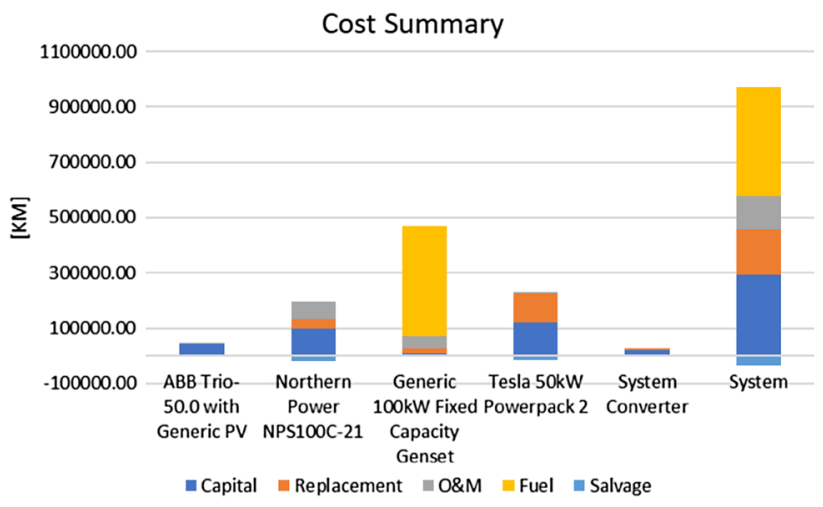

Fig. 2 Cost summary

\subsection{DIgSILENT PowerFactory}

In this section, two modes of operation, grid-connected and island mode, will be presented. The winter and summer scenarios will be shown separately with focus on four important segments of analysis: the power flow in and out of the microgrid, voltage profiles (worst-case scenario), line and transformer loadings (worst-case scenarios) and total grid losses.

The power of every transformer was provided as well as the load characteristics of TS Luka and TS Odžaci. It was necessary for the analysis to enter the load characteristic for each transformer in the observed network, but due to the lack of data, the provided characteristics were used as an approximation on the rest of the transformers taking the relevant maximum power into consideration. It was possible to make these approximations due to the similar load characteristics of households.

For winter scenario, 2 days were chosen, specifically 13th January and 11 th February, both working days. After shorter analysis, it was stated that there was no bigger difference between working days and weekends in winter.

There were no changes in the summer scenario regarding the methodology of calculations on the obtained data. The only difference compared to the winter scenario is the days chosen for analysis. The load characteristics for summer include 19th July and 20th August. The first one is a work day and the latter is a day of the weekend, chosen
Table 3 Net present costs (all values presented in $\mathrm{KMs}$ )

\begin{tabular}{lrllllc}
\hline Component & Capital & Replacement & O\&M & Fuel & Salvage & Total \\
\hline ABB Trio-50.0 with generic PV & 45,000 & 0.00 & 3232 & 0.00 & 0.00 & 48,232 \\
Northern power NPS100C-21 & 100,000 & 31,881 & 64,638 & 0.00 & $-17,967$ & 178,551 \\
Generic 100 kW fixed capacity Genset & 8000 & 19,743 & 43,113 & 396,166 & -846.44 & 466,176 \\
Tesla 50 kW Powerpack 2 & 120,000 & 106,013 & 6464 & 0.00 & $-14,373$ & 218,103 \\
System converter & 19,792 & 8397 & 0.00 & 0.00 & -1580 & 26,608 \\
System & 292,792 & 166,033 & 117,446 & 396,166 & $-34,767$ & 937,670 \\
\hline
\end{tabular}




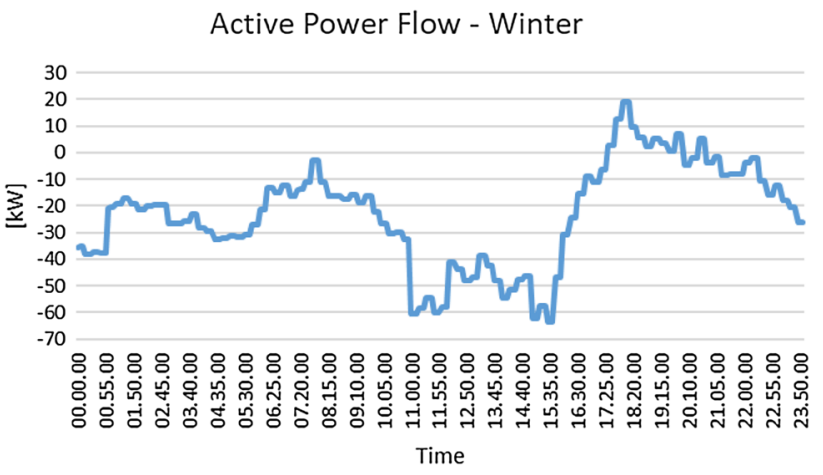

Fig. 3 Active power flow in the microgrid-GC mode, winter scenario

due to the expected household load characteristic. Again, these characteristics were used for approximation on loads for which there was no measurement data provided.

\subsubsection{Grid-connected mode, winter scenario}

After implementation of the input characteristics explained in Sect. 2, the quasi-dynamic simulation was performed, which is an automated load flow calculation for longer time periods (in this case 1 day) with 5-min step of simulation. In the following subsections, the results will be shown and explained.

Power flow will be observed from the line that is closest to the switch which separates microgrid from the rest of the network. The negative values of active power present the power returned to the network due to the higher production than consumption. The active power flow is shown in Fig. 3.

After shorter analysis, it is concluded that the worstcase scenario of voltage profiles belongs to the TS Luka, with minimum value of 0.984 [p.u.] and maximum value 0.994 [p.u.]. The voltage profile of this scenario is shown in Fig. 4.

Analysis has shown that the largest loadings are present on Line (29) and on TS Luka transformer. The maximum loading (\%) is $3.81 \%$ on the mentioned line, and the complete line loading is shown in Fig. 5. The maximum loading on transformer is $38.76 \%$, and the complete transformer loading is shown in Fig. 6.

The total grid losses have a peak value at $5.482 \mathrm{~kW}$, and it can be observed from Fig. 7, which shows losses of active power in one characteristic day in winter.

Grid-connected mode in winter period shows that the most influenced line and transformer are those closest to the wind turbine and that was an expected observation when the increased generation is taken into consideration. A larger amount of energy is returned to the grid due to the lower energy consumption.

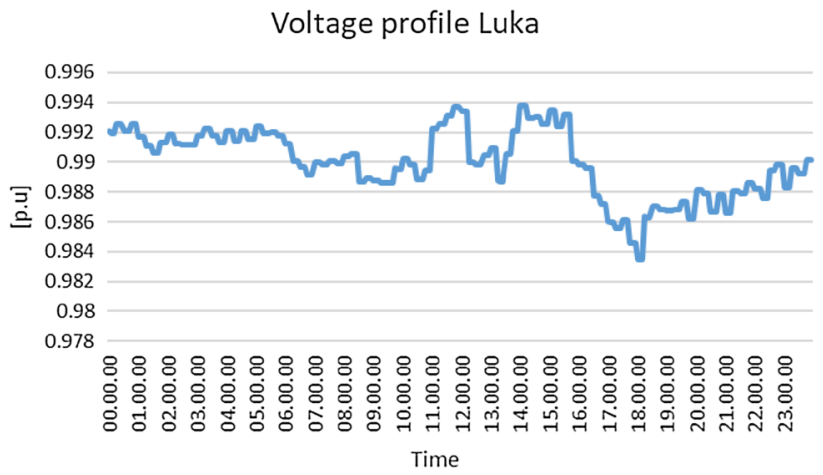

Fig. 4 Voltage profile of the worst-case scenario-GC mode, winter scenario

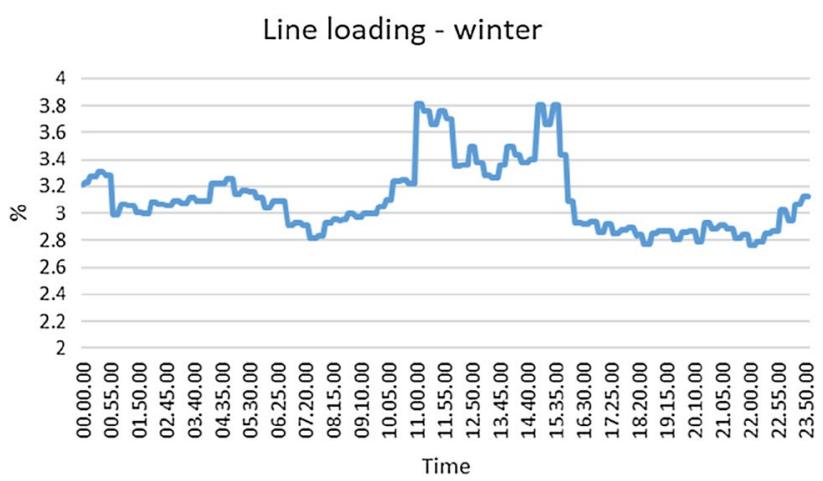

Fig. 5 Line loading - GC mode, winter scenario

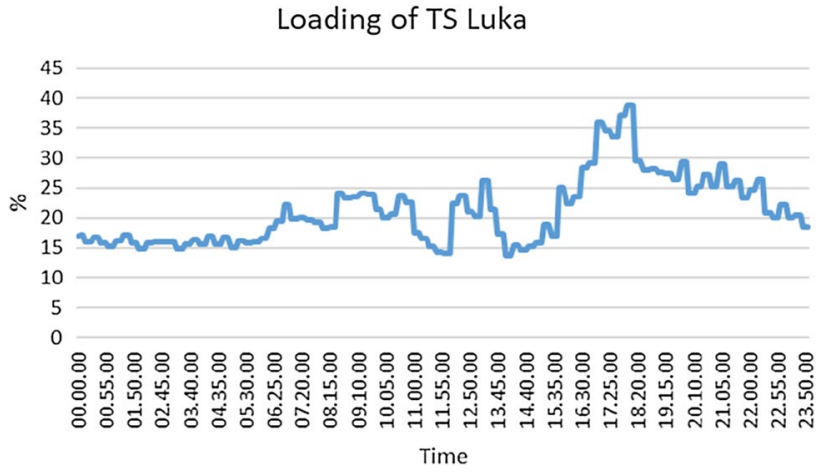

Fig. 6 Transformer loading - GC mode, winter scenario

\subsubsection{Grid-connected mode, summer scenario}

The active power that goes in and out of the planned microgrid is observed from the line that connects microgrid with the rest of the network. The power flow in summer period is shown in Fig. 8.

The worst-case scenario regarding the voltage variations across the network is observed again on TS Luka. 
Total grid losses - winter

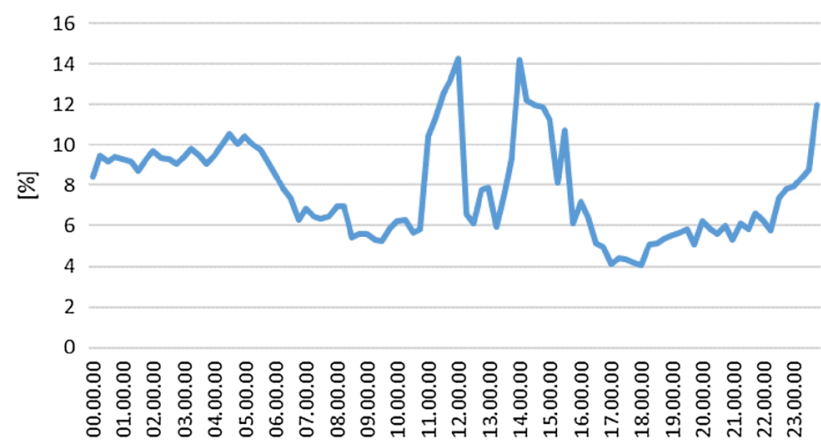

Fig. 7 Total grid losses-GC mode, winter scenario

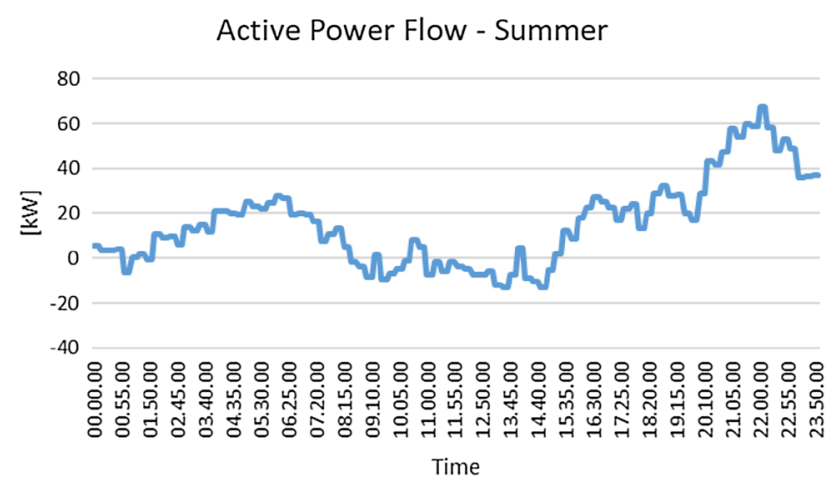

Fig. 8 Active power flow in the microgrid-GC mode, summer scenario

The maximum value of the voltage [p.u.] is 0.990 and minimum value is 0.979 [p.u.]. Neither one of these variations goes above or below the tolerance range of $10 \%$. The voltage profile along one summer day is presented in Fig. 9.

Analysis has shown that the largest loadings are present again on Line (29) and on TS Luka transformer. The maximum loading is $3.824 \%$ on the mentioned line, and the complete line loading is shown in Fig. 10. The maximum loading on transformer is $47.64 \%$, and the complete transformer loading is shown in Fig. 11.

The total grid losses have a peak value at $5.646 \mathrm{~kW}$, and it can be observed from Fig. 12, which shows losses of active power in one characteristic day in summer.

Conclusions like those from grid-connected mode in winter scenario can be drawn here as well. Voltage variations caused by increased production and lower consumption do not exceed $2 \%$, which means that the voltage remains in tolerance range. Losses in summer and winter periods are both in the range $4-14 \%$.

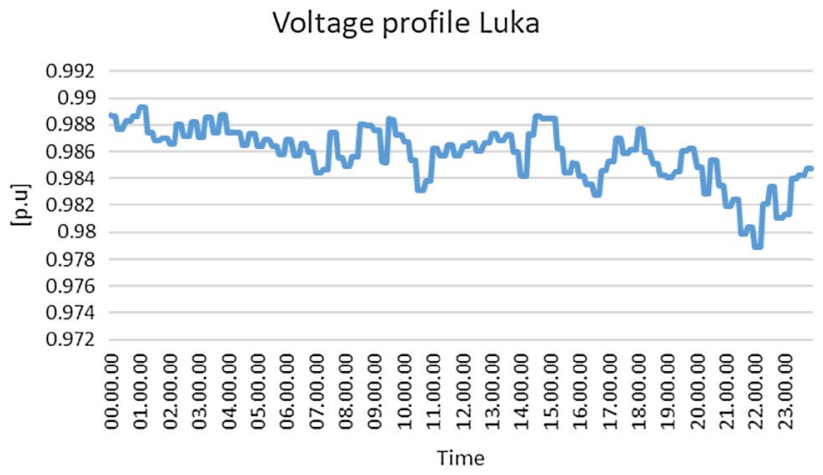

Fig. 9 Voltage profile of the worst-case scenario-GC mode, summer scenario

Line loading - summer

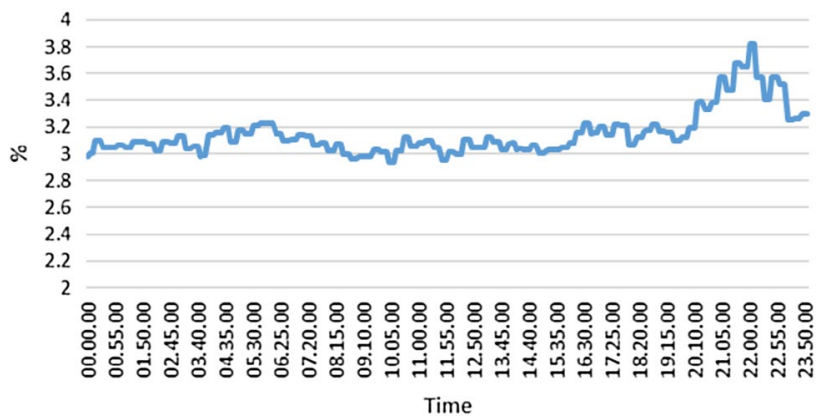

Fig. 10 Line loading - GC mode, summer scenario

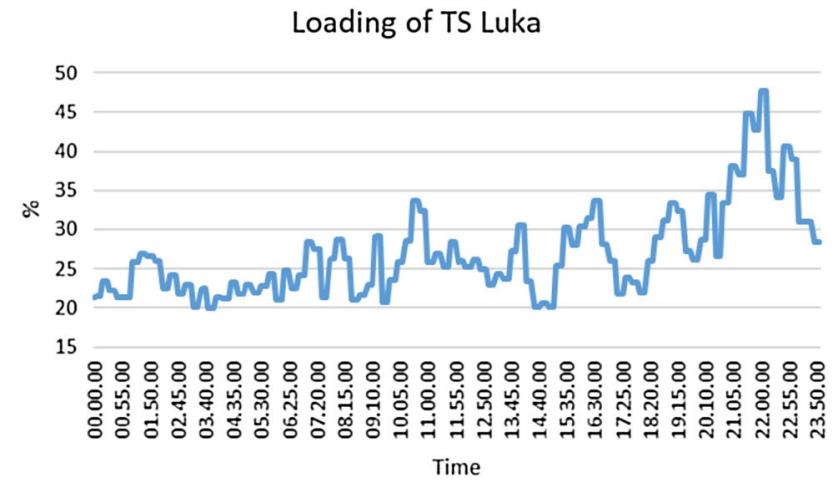

Fig. 11 Transformer loading - GC mode, summer scenario

\subsubsection{Island mode, winter scenario}

Regarding the line closest to the switch that separates the microgrid from the rest of the network, it is unnecessary to observe the active power flow now when the microgrid is operating in "island mode." That line now transmits no power comparing to the grid-connected scenarios. 
Total grid losses - summer

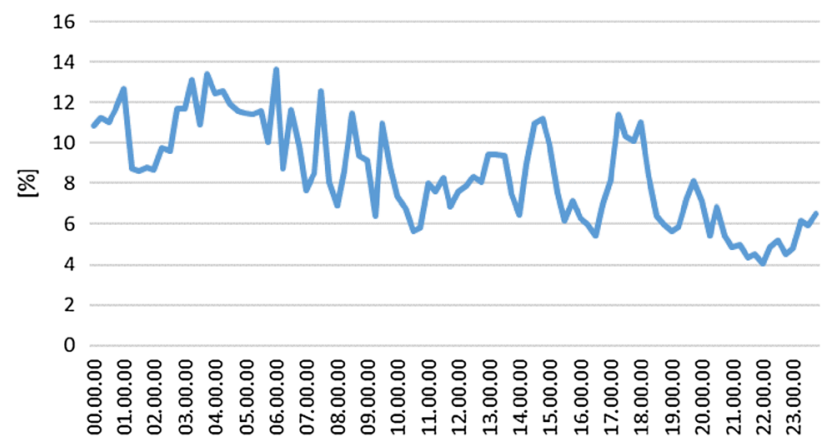

Fig. 12 Total grid losses-GC mode, summer scenario

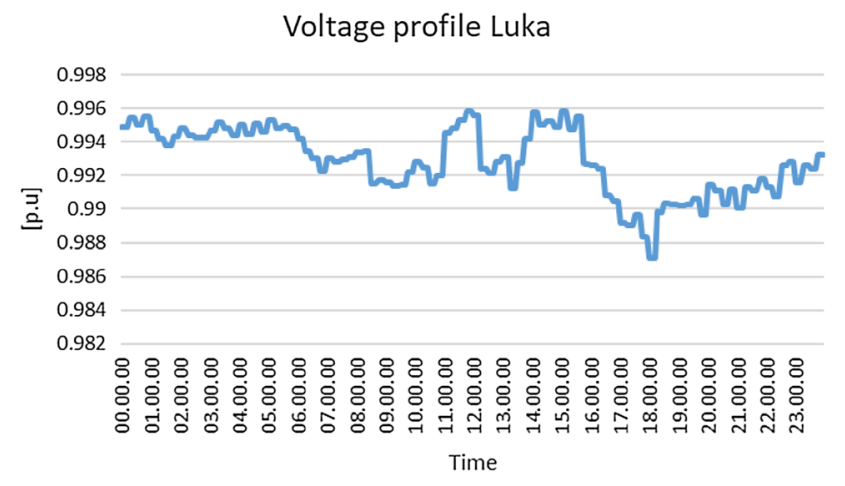

Fig. 13 Voltage profiles-island mode, winter scenario

When compared to the grid-connected winter scenario, voltage profiles are still within the range of tolerance, and there are less variations within that range. The minimum value is 0.987 [p.u.], and maximum value is 0.996 [p.u.]. Voltage profiles are shown in Fig. 13.

The worst-case line loading described in the grid-connected scenarios has decreased for several percent when the microgrid is in island mode. The maximum loading (\%) is $0.45 \%$ on the Line (29) and the complete line loading is shown in Fig. 14. The transformer loading is similar to the one described in Sect. 3.2.1, and the maximum loading on transformer is $38,644 \%$. Complete transformer loading is shown in Fig. 15.

The total grid losses have a peak value at $5.326 \mathrm{~kW}$ which is slightly lower than losses in grid-connected mode. It can be observed from Fig. 16.

Island mode in winter period brings several improvements regarding the grid-connected mode. The voltage variations are reduced and line loading is decreased, while the transformer loading and total grid losses are same for both modes. The most important conclusion is that the system may be sustainable with the proposed system architecture.
Line loading - winter

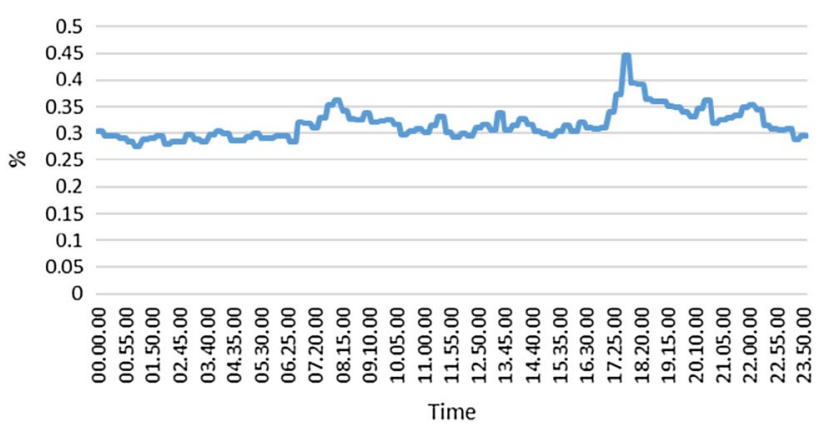

Fig. 14 Line loading-island mode, winter scenario

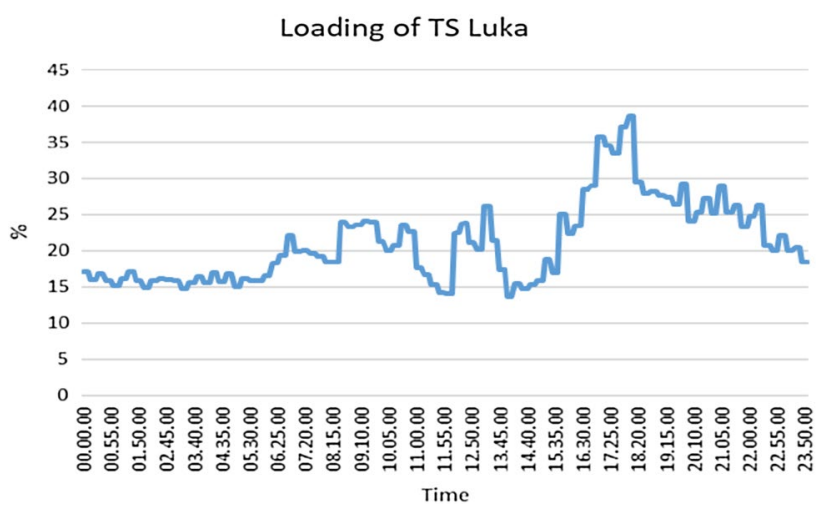

Fig. 15 Transformer loading-island mode, winter scenario

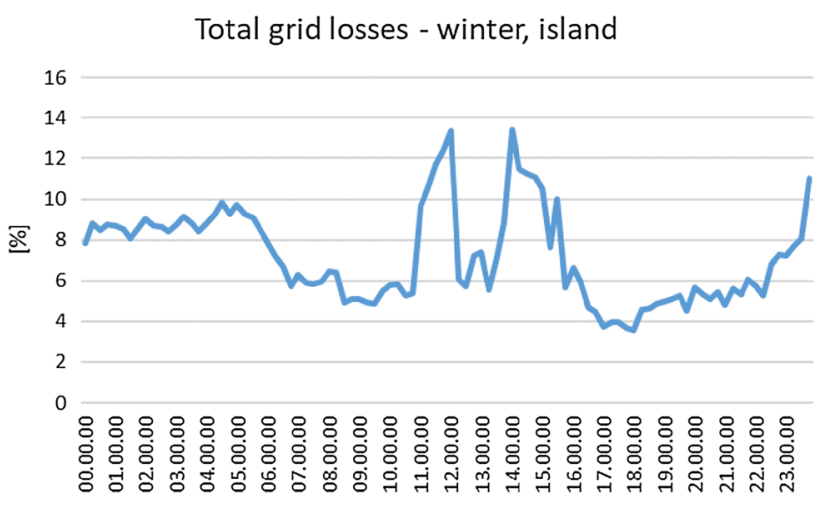

Fig. 16 Total grid losses_-island mode, winter scenario

\subsubsection{Island mode, summer scenario}

Similar to the winter scenario, voltage profiles are still within the range of tolerance compared to the grid-connected mode and there are less variations within that range too. The minimum value is 0.994 [p.u.], and maximum value is 0.985 [p.u.]. Voltage profiles are shown in Fig. 17. 


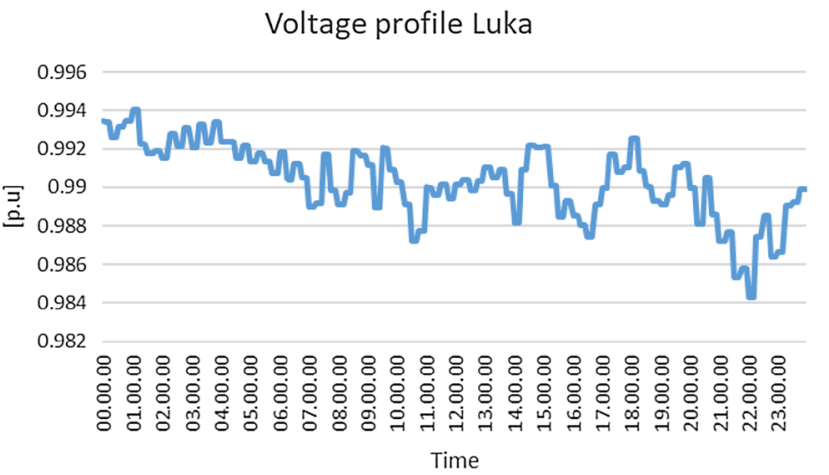

Fig. 17 Voltage profile-island mode, summer scenario

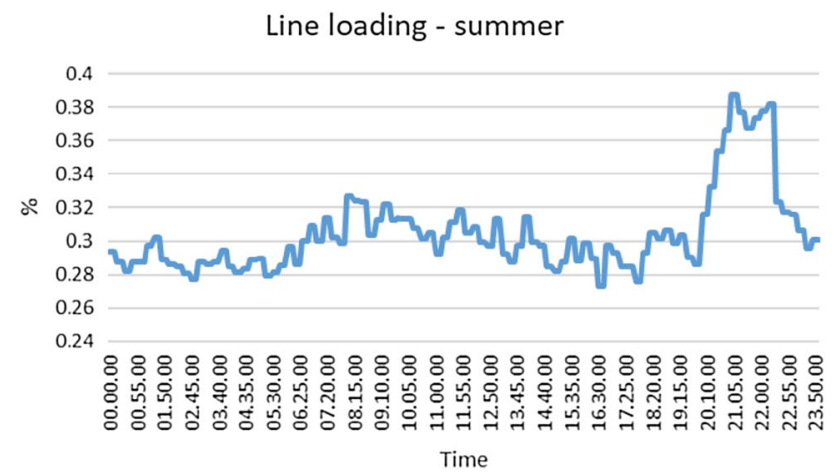

Fig. 18 Line loading-island mode, summer scenario

The worst-case line loading described in the grid-connected scenarios has decreased for several percent when the microgrid is in island mode. The maximum loading (\%) is $0.384 \%$ on the mentioned line (29), and the complete line loading is shown in Fig. 18. The transformer loading is similar to the one described in Sect. 3.2.2, and the maximum loading on transformer is $47.5 \%$. Complete transformer loading is shown in Fig. 19.

The total grid losses have a peak value at $5.41 \mathrm{~kW}$, and it can be observed from Fig. 20, which shows losses of active power in one characteristic day in summer when in island mode.

Island mode in summer period shows the same improvements as for the winter scenario. Voltage profiles have been improved, and the loading of the observed line has been reduced. The loading of distribution transformers stays the same, since the load stays the same in both grid-connected and island modes.

SN Applied Sciences

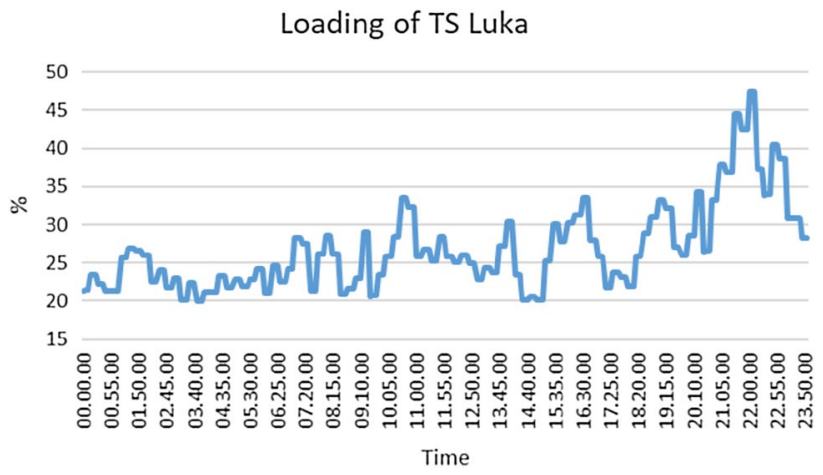

Fig. 19 Transformer loading —island mode, summer scenario

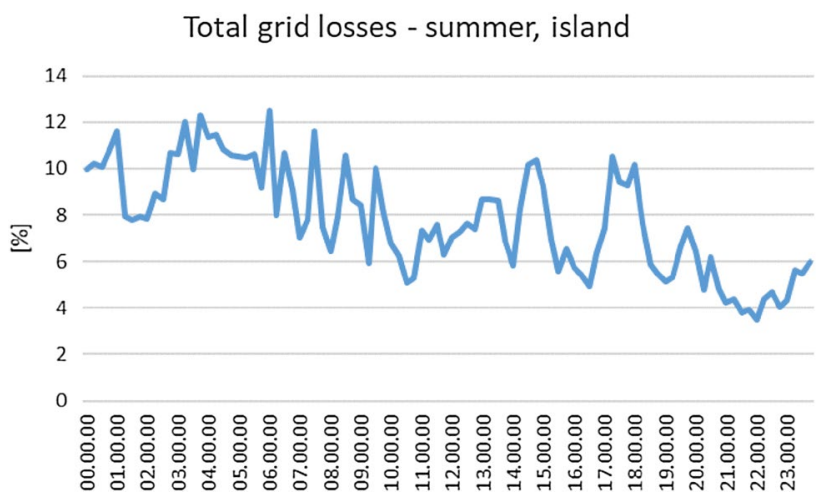

Fig. 20 Total grid losses-island mode, summer scenario

\section{Conclusion}

A way to optimally size and to evaluate the cost of energy produced by a hybrid power system was proposed in this project. The total NPC cost of the HPS is higher than costs of electricity bought from centralized production units. However, electricity from a centralized system requires high costs of MV network construction as well as losses in the MV network; $1 \mathrm{~km}$ of main MV overhead line with uninsulated conductors costs approx. $65,000 \mathrm{KM}$, and there are tens of kilometers of main MV overhead line. Besides, this implementation will lead to $\mathrm{CO}_{2}$ emissions reduction and many other social and consumers' satisfactions. In any case, when considering the construction or significant upgrading of networks for such and similar areas, microgrids should be considered as excellent solution.

Analyses in DIgSILENT PowerFactory software have confirmed that HPS and microgrid can operate within the limits of permitted voltage variations and without overloading of any of the elements in either case, gridconnected or island modes. 
After detailed analysis and the result presentation, it is evident that there are better conditions of the network when it is in the island mode. That conclusion can be drawn either from winter or summer scenarios.

In addition, prior to the implementation of the microgrid, many other aspects, such as stability of microgrid, protection, management of network components based on the prediction of consumption and prediction of production from RES, should be analyzed.

\section{Compliance with ethical standards}

Conflict of interest The authors declared that they have no conflict of interest.

\section{References}

1. Definition of Hybrid Power Systems, CRES, Greece. http://www. cres.gr/hypos/files/fs_inferior01_h_files/definition_of_hps.htm

2. Merzic A, Music M, Rascic M, Hadzimejlic N (2016) An integrated analysis for sustainable supply of remote winter tourist centers-a future cocept case study. Tubitak 24:2821-3837

3. Hassan Q, Jaszezur M, Abdulateef J (2016) Optimization of PV/WIND/DIESEL hybrid power system in HOMER for rural electrification. In: 7th European thermal-sciences conference (Eurotherm2016)

4. Morris GY, Abbey C, Wong S, Joos G (2012) Evaluation of the costs and benefits of Microgrids with consideration of services beyond energy supply. In: 2012 IEEE Power and Energy Society General Meeting, July 2012

5. Wang M, Li Y, Zhang C, Cai D, Yuan Y (2013) Dynamic simulation of a microgrid with renewable microsources based on DigSILENT/PowerFactroy, China, ICAEES 2013

6. Mehrizi-Sani A (2011) Control strategies for the next generation microgrids, University of Toronto

7. The role of microgrids in helping to advance the nation's energy system, ENERGY.GOV, https://www.energy.gov/oe/activities/ technology-development/grid-modernization-and-smart-grid/ role-microgrids-helping

8. Jovanovac I (2016) Mikromreže. Sveučilište Josipa Jurja Strossmayera u Osijeku

9. Hatziargyriou N (2014) Microgrids: arhitectures and control, Wiley-IEEE Press, Greece

10. Soni KC, Belim FF (2015) Microgrid during grid-connected mode and islanded mode - a review. In: National conference on recent research in engineering and technology

11. Load following strategy, Homer Energy Support. https://www. homerenergy.com/products/pro/docs/3.10/load_following_ strategy.html 